\title{
ESTADO Y MERCADO
}

Juan Felipe Botero Gómez

Estudiante Facultad Economía Empresarial

\section{Anfora}

s importante tener en cuenta que la ciencia económica tiende a ser mas abstracta que concreta, ya que todas sus leyes, teorías y modelos no pasan de ser simples tendencias que describen ciertos comportamientos, por lo cual no se puede mas que decir, que las leyes económicas sólo se cumplen en promedio y no como relaciones exactas.

Por todo ésto resulta insólito pensar cómo hay quienes, sustentados en la teoría clásica, quieran promover para países en vía de desarrollo, como los latinoamericanos, un modelo neoliberal de desarrollo que lleva a estas economías a abrirse al mundo, entrando a competir con países que le llevan años, por no decir que siglos de ventaja. Esto se sustenta en el hecho de que estos modelos neoliberales le dan toda la autonomía al mercado, como amo y señor del funcionamiento de la economía, sustentado en ciertos supuestos que en la realidad no dejan de ser utópicos, y por lo tanto los resultados nunca podrán ser los esperados. 
También es importante tener en cuenta, que los creadores de este modelo de desarrollo pertenecen a los países industrializados que son los mismos que por medio de su poder en los grandes organismos internacionales promueven este modelo de desarro-

llo para nuestras economías, sabiendo que los beneficios a largo plazo serán todos para ellos.

De otro lado, resulta insólito ver como mientras aquí nos promueven la apertura al comercio internacional y la no intervención estatal, los países desarrollados conforman grupos económicos cerrados entre ellos con una marcada intervención y tendencia netamente conservadoras.

En este proceso neocolonizador del mundo industrializado hacia los países periféricos, además de la intervención por medio de los organismos internacionales, es palpable también la búsqueda de implantar democracias pro-norteamericanas que no opongan resistencia alguna a los mandatos del norte.
De esta forma los países latinoamericanos se han embarcado durante los últimos años en este proceso de liberación económica con predominio de las fuerzas del mercado, como principal sujeto del modelo de desarrollo, con los primeros resultados nefastos a la vista, como lo es la crisis mexicana, país este que fue de los primeros en implantar el proceso de apertura y que por su gran importancia a nivel económico en latinoamérica. sirve como marco de referencia a muchos más países que copian sus modelos y medidas económicas.
Lo que realmente sucede, es que este modelo en la forma acelerada en que se ha llevado, sólo puede llevar a un colapso, pues si bien en un momento determinado se logra un mejoramiento en ciertos indicadores macroeconómicos, como un leve crecimiento del P. I. B., una inflación más controlada y un superávit fiscal; de otro lado, está un creciente déficit en cuenta corriente ante la mayor 
competitividad de los productos extranjeros que arrasan con la industria nacional. pudiendo sobrevivir unas pocas empresas que tienen cierta capacidad financiera sustentada en el poder de los grandes grupos económicos. De esta forma, la reducida clase alta de la sociedad cada vez se consolida más; tienden a desaparecer las clases medias y a profundizarse la pobreza hacia los límites de la miseria, todo ésto, reforzado por las restricciones a la actividad estatal que le otorga al sistema.

En pocas palabras, el proceso pone en competencia al pez grande con el pequeño, con los resultados obvios de esta confrontación.

Es por ésto por lo que la intervención estatal como ente regulador en pro de su función social es básica. Pero para ésto se necesita un nuevo Estado, un Estado moderno, con la suficiente autonomía apta poder tomar decisiones que vayan en beneficio de su gente que es la razón de ser del Estado.
No se puede olvidar que la economía es una ciencia social y como tal. los resultados de esta deben estar encaminados a lograr el bienestar del hombre, antes que el beneficio económico. Es así como la rentabilidad y el beneficio son el objetivo del sector privado, mientras el Estado debe estar por encima del mercado para lograr por medio de su intervención, que esos beneficios económi$\cos$ del sector privado redunden en beneficios sociales para toda la población.

Teniendo en cuenta que para lograr el desarrollo económico es básico integrarse al mercado mundial de una manera adecuada, este objetivo nunca se va a lograr si se continúa teniendo como soporte las exportaciones de bienes naturales por lo general no renovables; es necesario añadir algo más de valor agregado con base en tecnología que permita un desarrollo sostenible a través del tiempo. Es ahí donde se necesita un Estado con visión de mercado que se preocupe por brindar una infraestructura adecuada que par- 
ta de un buen sistema educacional que garantice a toda la población la posibilidad de acceder a él, una redistribución de la renta que ataque la concentración de la riqueza para lograr un ambiente social óptimo que garantice una seguridad interior que motive la inversión y así, evitar ese sobrecosto tan alto que representa la inseguridad promovida por la pobreza y las desigualdades sociales.

Así se solidificaría la economía para luego poder entrar en forma pausada a participar de una manera adecuada en la integración del mercado mundial, con la seguridad de que a la vez que se abren las fronteras de un lado, se brinde iguales oportunidades del otro. En la medida en que se cuente con una sociedad solidificada, a la vez que se logra una integración con el mercado mundial, también se logra una inserción social al mundo, es decir, se debe partir del concepto básico de que lo social debe llevar al mercado.

De esta manera se lograría el auge de una «Economía social de Mercadow que permitiría un verdadero desarrollo para los países latinoamericanos con un sector privado sólido y pujante y un Estado que cumpla su principal función que es lo social, basado en el progreso del sector privado, pues no se debe olvidar que tanto el Estado como el mercado se complementan el uno al otro, 